\title{
A ESCRITA DO INCONSCIENTE NO TEXTO TRADUZIDO ${ }^{1}$
}

Maria Paula Frota é doutora em Linguística pela UNICAMP e docente no Departamento de Letras da PUC-Rio, especificamente no Curso de Tradução e no Programa de Pós-Graduação Estudos da Linguagem. Teve ampla experiência como tradutora de textos não ficcionais. Estudou na Escola Letra Freudiana do Rio de Janeiro e escreveu A singularidade na escrita tradutora: linguagem e subjetividade nos estudos da tradução, na linguística e na psicanálise.

Email: mpfrota@puc-rio.br

\section{Resumo}

Este artigo investiga a escrita do inconsciente no âmbito do processo tradutório. Parte da desconstrução do subjetivismo e trabalha centralmente com a noção freudiana de lapso de lingua.

\begin{abstract}
This article investigates the writing of the unconscious in the process of translation. Assuming the deconstruction of subjectivism, its central reference is the Freudian notion of verbal slip.
\end{abstract}

Conto logo ao início uma breve história, atribuindo a ela a função de epígrafe:

Uma tradutora de filmes bastante experiente contou-me, já há um tempo, que havia traduzido rocking chair ("cadeira de balanço") por "cadeira de rodas" (wheelchair), na canção "Enjoy yourself, it's later than you think", a qual integra o musical Todos dizem eu te amo, de Woody Allen. Sabedora de meu interesse por tropeços tradutórios, minha amiga tradutora enviou-me um e-mail, primeiro passo desta nossa história:

algumas semanas antes da estreia nacional do filme, mas depois que ele já havia sido legendado pelo laboratório, acordei de madrugada sobressaltada, com a certeza de que havia um equívoco na tradução de um dos números musicais. Fui para o computador e repassei todas as canções uma a uma, até que me deparei com ele.

Fiquei extremamente curiosa, fui atrás dos detalhes e tivemos então uma interessante conversa da qual partes e premissas tento aqui costurar. É preciso logo dizer que, no filme, o contexto do número musical em questão (cujo título condensa muito bem a lição de vida que quer passar) é o velório de um avô cujo fantasma levanta-se do caixão e diz à sua família, ali reunida, que, a continuarem trabalhando tão compulsivamente, suas vidas vão passar e, antes que percebam, estarão todos presos a uma cadeira de balanço (de rodas?). Também é preciso dizer que a prestigiada tradutora morou por diversos anos nos Estados Unidos, onde fez mestrado em literatura, e que, portanto, aquilo que estava julgando "um terrível ato falho" era mesmo um ato falho ou, melhor dizendo, um lapso de língua, já que com certeza não se havia produzido a partir de desconhecimento ou ignorância de um termo tão usual como rocking chair - talvez por isso mesmo se sentisse "arrasada". Não sendo eu psicanalista, mas leitora atenta de Freud, ative-me a observar, como linguista e tradutora, que o seu lapso ("lapso de tradução", cunhemos o termo) acabara sendo, felizmente, um bom erro, se consideramos que em nossa cultura brasileira cadeiras de balanço, muito utilizadas pelas

Revista Escrita

Rua Marquês de São Vicente, 225 Gávea/RJ CEP 22451-900 Brasil

Ano 2013. Número 17. ISSN 1679-6888.

escrita@puc-rio.br 
mães para ninar seus bebês, ou para amamentá-los, parecem funcionar mais como um símbolo de vida do que como metáfora para velhice e doença. Independentemente de preferência por essa ou aquela opção, encerro a história com a interpretação autorizada da tradutora quanto a uma provável motivação do lapso: sua identificação inconsciente com aquela família do filme e com aquelas recriminações do avô-fantasma, já que ela, também uma workaholic, vinha há tempos traduzindo sem parar, em seu escritório, sentada na sua cadeira de trabalho, que, como de praxe, tem rodinhas, encontrando-se, portanto, presa a uma cadeira de...

Meu ponto de partida teórico é a percepção de que a maioria dos estudos sobre a tradução não investiga uma esfera necessariamente implicada no ato tradutório: o inconsciente. Nesses estudos, o sujeito é concebido como efeito de valores socioculturais e determinantes histórico-ideológicos, mas, salvo exceções, nada se diz sobre o desejo do inconsciente, sobre o nosso inescapável assujeitamento a essa dimensão de poderosos pensamentos que acontecem à nossa revelia. Neste artigo, destaco o que parece ser a causa dessa lacuna, e proponho a psicanálise - em particular sua noção de sujeito do inconsciente - como o único caminho capaz de superá-la. ${ }^{2}$

Uma das principais propostas dos estudiosos nas últimas, digamos, quatro décadas, tem sido lutar contra a invisibilidade da tradução e a incompreensão que a cerca em todas as sociedades, incluídos os seus espaços acadêmicos. Como Lawrence Venuti escreveu, "o fato da tradução tende a ser ignorado até pelos estudiosos mais sofisticados que necessitam de textos traduzidos para suas atividades de pesquisa e docência" (1996, p. 112). Buscando transformar a tradução em uma atividade socialmente visível e prestigiada, resgatando-a da desinformação generalizada e da invisibilidade às quais tem sido tradicionalmente relegada, os teóricos concentram seus ataques na noção subjetivista de sujeito que relacionam à filosofia de Descartes, ao liberalismo, ou ao romantismo alemão. E por que atacar essa noção subjetivista de sujeito? Porque é essa noção que subjaz à crença de que o autor é um indivíduo livre ou autônomo cuja própria razão é a única origem de seu trabalho. E é essa crença, por sua vez, que implica o baixo status da atividade do tradutor e o imperativo de que este deve permanecer passivo e neutro, não deve contaminar a obra "sagrada" do Autor. Essa situação conceitual foi resumida por Theo Hermans com muita nitidez:

A principal raiz de tais visões [visões sobre linguagem e literatura que negligenciam a tradução] parece situar-se em uma série de conceitos ingenuamente românticos de "gênio artístico", "originalidade", "criatividade" [...] Se o artista literário é visto como um gênio criativo incomparavelmente dotado, com profundo conhecimento e mestria de 
sua língua nativa, o trabalho que ele produz será naturalmente visto como superior, intocável, inimitável, abençoado. (Hermans, 1985, p. 7)

Venuti desenvolve praticamente o mesmo argumento:

Enquanto a autoria é definida como originalidade, autoexpressão num texto singular, a tradução é derivada, nem autoexpressão, nem singular: imita outro texto. Dado o conceito reinante de autoria, a tradução provoca o temor de inautenticidade, distorção, contaminação. (1996, p. 111)

Desconstruindo essa situação, os teóricos (inspirados por Michel Foucault, Roland Barthes e outros) salientam a ideia de que ninguém é livre ou autônomo; que todos, e consequentemente todas as suas atitudes, estão subordinados a valores culturais e forças históricas. Essa visão necessariamente implica que não podem existir nem a autoria como criatividade puramente individual, nem a tradução como atividade absolutamente neutra. Quanto à autoria, argumenta-se que, se a subjetividade não é nem auto-originada, nem transcendental, mas determinada, o trabalho do autor reflete toda a sua experiência social e cultural, aí incluídos todos os textos que leu - nesse sentido, toda escrita é uma reescrita de textos preexistentes. Quanto à tradução, argumenta-se que, se não é possível livrar-se da própria bagagem sociocultural, que influencia tudo o que se faz, a leitura e a escrita do tradutor são, sem dúvida, mediadas por ela - nesse sentido é impossível o apagamento do sujeito que traduz. André Lefevere e Susan Bassnett, como organizadores, escreveram o seguinte no prefácio de todos os livros da coleção Translation Studies Series, publicada pela Routledge:

A tradução é, claro, uma reescrita de um texto original. Toda reescrita, qualquer que seja sua intenção, reflete uma certa ideologia e uma poética e, enquanto tal, manipula a literatura de modo a que ela funcione, em uma dada sociedade, de determinada maneira. (ver, por exemplo, Gentzler, 1993, p. ix)

Bastante inspirados no pós-estruturalismo, os estudiosos da tradução propõem que autores, tradutores e leitores sejam concebidos como sujeitos sociais, sujeitos históricos, e, em reação a teorias linguísticas identificadas com a linguística saussuriana da langue, eles propõem uma visão de língua não como um sistema homogêneo abstrato, mas como uso, ou como um sistema heterogêneo totalmente imbricado com formações culturais e circunstâncias históricas. É óbvio que a perspectiva universalista da linguagem e do sentido não é mais uma alternativa viável entre tais teóricos; as noções de contexto e de diferença estão, de modo geral, bem estabelecidas nos estudos da tradução. Se as culturas são diferentes e se o significado é determinado pelo contexto, ${ }^{3}$ só se pode rejeitar a ideia de tradução como transporte transparente de intenções e significados permanentes de um original, redefinindo-se a tradução como

Revista Escrita

Rua Marquês de São Vicente, 225 Gávea/RJ CEP 22451-900 Brasil

Ano 2013. Número 17. ISSN 1679-6888.

escrita@puc-rio.br 
transformação. Em uma entrevista dada a Julia Kristeva, Jacques Derrida fez a tão citada proposta:

seria necessário substituir a noção de tradução pela de transformação: uma transformação regulada de uma língua por outra, de um texto por outro. Não se tratou, nem, na verdade, nunca se tratou de alguma espécie de "transporte", de uma língua à outra, ou no interior de uma única e mesma língua. (2001 [1972], p. 26)

Ainda que a partir de posições teóricas distintas e valendo-se de formas menos ou mais explícitas, o processo de tradução como transformação ou como reescrita manipuladora tem sido considerado, então, principalmente no que diz respeito aos seus aspectos socioculturais, históricos e políticos. As transformações inevitáveis são atribuídas a diferenças culturais e linguísticas, a uma função específica que é exigida de determinado texto traduzido na cultura alvo, à patronagem, e assim por diante. Mas pouquíssimos trabalhos investigam a intervenção do inconsciente nesse processo. ${ }^{4}$ Essa parece ser uma lacuna grave, pois, como afirmou Lacan em A instância da letra no inconsciente ou a razão desde Freud, "a eficiência do inconsciente não se detém no despertar. A experiência psicanalítica não é outra coisa senão o estabelecer que o inconsciente não deixa nenhuma de nossas ações fora de seu campo" (1978, p. 245). O que podemos aprender com essas palavras é que o inconsciente opera vinte e quatro horas por dia em todas as nossas ações e, portanto, não só em nossos sonhos ou quando nos deitamos no divã do consultório do psicanalista. Em $O$ ego e o id (ou, em tradução direta, $O$ eи e o isso) Freud afirma que os desejos e pensamentos inconscientes intervêm "mesmo [em] operações intelectuais sutis e difíceis, que ordinariamente exigem reflexão vigorosa" (1996, v. XIX, p. 40). Parece, portanto, bastante relevante e necessário voltarmos nossa atenção para a psicanálise, a fim de entendermos melhor o processo tradutório e, em especial, o sujeito que traduz.

No âmbito dos estudos da tradução, a morte do sujeito cartesiano foi proclamada mas aparentemente poucas investigações foram feitas para, a partir daí, reconceber-se a esfera do indivíduo, pensar-se a subjetividade não só em termos de sua constituição sociocultural, mas também em termos de um plano menos amplo, uma dimensão particular e singular. É nesse sentido que a psicanálise, ao conceber o inconsciente, sua estrutura e funcionamento, aparece como alternativa única ao subjetivismo. O que a torna diferente de outras teorias é que, sem negligenciar as dimensões históricas e culturais, a psicanálise vai além (aquém?) delas. Isso acontece porque, de acordo com a proposição teórica freudiana, o sujeito está incontestavelmente subordinado, assujeitado à língua, à história e à cultura, ${ }^{5}$ mas esse assujeitamento está misturado com o assujeitamento operado pelo desejo, o qual é marcado por uma profunda singularidade, 
constituída, por assim dizer, pela história do sujeito - por restos de palavras ouvidas e de imagens vistas ao longo de sua vida, particularmente em sua infância (ver Freud, 1996, v. XIX).

Para trazer a este artigo um pouco do sujeito do inconsciente, do desejo inconsciente, relacionando-o ao tradutor, o melhor a fazer, creio, é recorrer às próprias obras de Freud. E, dado que o tradutor aqui prioritariamente em foco lida com textos escritos, sendo ler e escrever suas principais atividades, proponho recorrermos ao livro A psicopatologia da vida cotidiana, cuja primeira versão data de 1901, pois é aí que Freud constrói o conceito de lapso de língua e investiga, por meio de ocorrências desse lapso, a escrita do desejo inconsciente nos textos. Pela mesma razão, proponho que nos concentremos nos lapsos de leitura e de escrita. ${ }^{6}$

Freud concebe o lapso de língua como um erro inconsciente resultante de um evento psíquico que consiste no esquecimento momentâneo de uma expressão correta e no aparecimento em seu lugar de uma expressão incorreta, produzida por uma ilusão da memória. A expressão incorreta tem uma conexão associativa com a expressão esquecida e, mais importante, com algum outro material - um pensamento ou um desejo - que está sendo recalcado. Esse material recalcado, inconsciente, "luta" com as intenções conscientes e pode exercer sobre elas uma influência perturbadora, sendo às vezes pelo menos parcialmente bem sucedido (ver Freud, 1996, v. VI, p. 221). Essa luta do inconsciente para encontrar expressão ocorre sem que se saiba dela e, como mostrado no referido texto de Lacan, é permanente. Vale a pena enfatizar que "esses erros derivados do recalcamento devem ser claramente distinguidos de outros que se baseiam numa verdadeira ignorância” (Ibid., p. 220).

Embora o erro por ignorância constitua um acontecimento frequente na escrita tradutória, por isso merecendo a atenção dos estudiosos, sobretudo daqueles que se voltam para a crítica de traduções e para a formação profissional do tradutor (v. Frota, 2006), o nosso foco de interesse nesta reflexão recai sobre as operações psíquicas que constituem e caracterizam aqueles erros do primeiro tipo, isto é, erros que derivam de desejos recalcados e que são aqui tidos como meio para se compreender um pouco a complexa relação entre língua e sujeito do inconsciente. Apesar de não propor, no âmbito do presente artigo, trazer em minúcia a noção lacaniana de lalangue, gostaria de ao menos mencioná-la e observar que ela busca expressar exatamente aqueles momentos em que língua e desejo inconsciente se imbricam.

A percepção do espaço de expressão que o inconsciente encontra em nossos atos linguísticos deve-se ao modo como a psicanálise enxerga a linguagem em geral, e, mais especificamente, as línguas, objeto de nosso especial interesse. Freud reiteradamente chama a atenção para a equivocidade das palavras, para a indeterminação e fluidez dos sentidos. A visão da linguagem como equívoca, ou seja, como uma estrutura que,

Revista Escrita

Rua Marquês de São Vicente, 225 Gávea/RJ CEP 22451-900 Brasil

Ano 2013. Número 17. ISSN 1679-6888.

escrita@puc-rio.br 
flexível, não se fecha ao sujeito - e, complementarmente, da subjetividade como ocorrência na linguagem, nos "furos" que tal estrutura necessariamente comporta traz implicações da maior importância para a redefinição de ideais de equivalência ou fidelidade que até hoje norteiam muitos tradutores em suas práticas de trabalho.

Ainda que em diversas situações do nosso cotidiano, incluída a tradução, testemunhemos a ocorrência de lapsos, em geral ignoramos o que eles implicam e, assim, deixamos de apreciar seus possíveis sentidos. Visto que são falhos ou mesmo absurdos, nonsense, o mais comum é rejeitá-los. No entanto, como os lapsos de língua estão entre as formações típicas do inconsciente - junto com os sonhos, os atos falhos, os sintomas e os chistes - eles são preciosos para o trabalho do psicanalista na clínica. Os que escrevem, por sua vez, deveriam erradicar de seus textos tais erros incontestes, embora, com frequência maior do que gostaríamos, fiquemos "cegos" a eles e os deixemos escapar. Para tradutores e estudiosos da tradução, a relevância de compreender os lapsos de língua encontra-se no fato de eles expandirem nosso conhecimento acerca do que se passa "nos bastidores" de nossas leituras e escritas, de nossas traduções e reescritas em geral.

No livro que trata de nossas psicopatologias cotidianas, Freud relata dezenas de casos de atos falhos e lapsos de fala, de leitura e de escrita. A maioria deles foi cometida pelo próprio Freud, por médicos conhecidos seus ou por pacientes, de modo que ele estava em condições de analisá-los ou relatar análises alheias. Vale mencionar que a interpretação do lapso, como insistiu Freud, deve ser feita por quem o cometeu (talvez por seu psicanalista?), já que o lapso implica informações que as outras pessoas ignoram. Ocorre-me reforçar essa restrição com o caso da tradução de rocking chair por "cadeira de rodas": a história só se deu porque a tradutora identificou a sua escolha como um "ato falho"; um leitor-espectador do filme que porventura percebesse e estranhasse a escolha feita jamais poderia saber a respeito de sua proveniência - a escolha poderia perfeitamente ser fruto de uma elucubração pautada pela estratégia domesticadora de tradução, e, se assim tivesse sido, não existiria a história que abriu o presente trabalho. O que quero dizer é que para nós, tradutores, não interessa analisar os lapsos de outros; o que para nós é relevante, como já foi dito, é ter uma noção de como esses processos psíquicos ocorrem para entendermos minimamente o que o processo tradutório envolve naquilo que concerne ao inconsciente.

Vejamos agora (por meio da tradução indireta da editora Imago) um lapso cometido e analisado por Freud. Trata-se de um dos lapsos de escrita que cometeu quando escreveu $A$ interpretação dos sonhos e que também lhe passou despercebido em três revisões. Ele começa a ser apresentado da seguinte forma: 
Em meu livro A interpretação dos sonhos (1900) fui responsável por uma série de falseamentos do material histórico e factual em geral, nos quais reparei com assombro depois da publicação do livro. Investigando-os mais detidamente descobri que não haviam brotado de minha ignorância, mas remontavam a erros de memória que a análise poderia esclarecer. (Ibid., p. 217)

O primeiro desses lapsos que eu gostaria de apresentar é o lapso que ocorre quando Freud se refere ao pai de Aníbal não como Amílcar, mas como Asdrúbal Asdrúbal era, na verdade, o nome do irmão de Aníbal. Vale destacar a semelhança material dos três nomes, semelhança que Freud denomina "ponte verbal" e que, como ele explica, facilita o trabalho dos desejos recalcados, dos pensamentos inconscientes que insistem em se expressar, se escrever. Essas pontes geralmente ocorrem, embora às vezes sejam desnecessárias em face da força de tais desejos. Freud comentou:

Esse erro me foi especialmente aborrecido, mas foi o que mais corroborou minha concepção desses erros. Poucos leitores de meu livro hão de estar mais familiarizados com a história da casa dos Barca do que o autor, que escreveu esse erro e passou por cima dele em três revisões de provas. (Ibid., p. 217)

\section{E acrescentou:}

Como se explica que minha memória, nesses pontos, me fornecesse o que era incorreto, ao passo que, como pode comprovar o leitor do livro, colocava a meu dispor o material mais remoto e incomum? E mais, como foi que em três correções de provas, que fiz cuidadosamente, passei por esses erros como se estivesse cego? (Ibid., p. 218)

O próprio Freud respondeu a essas perguntas explicando que havia um recalcamento por trás do erro cometido:

O erro de escrever Asdrúbal em vez de Amílcar, o nome do irmão substituindo o do pai, ocorreu exatamente num contexto que se referia às fantasias sobre Aníbal em meus anos de ginásio e à minha insatisfação com o comportamento de meu pai frente aos "inimigos do nosso povo". Eu poderia ter prosseguido e contado como minha relação com meu pai foi alterada por uma visita que fiz à Inglaterra, onde vim a conhecer meu meio-irmão, filho do primeiro casamento de meu pai, que lá vivia. O filho mais velho de meu irmão tem a mesma idade que eu; assim, as relações entre nossas idades não constituíam nenhum obstáculo a minhas fantasias de como as coisas teriam sido diferentes se eu tivesse vindo ao mundo não como filho de meu pai, mas de meu irmão. Essas fantasias suprimidas falsearam o texto de meu livro no ponto em que interrompi a análise, forçando-me a colocar o nome do irmão em lugar do nome do pai. (Ibid., p. 219)

Outros dois lapsos, dessa vez de leitura, também nos ajudam a entender melhor a ação do inconsciente em nossas relações com textos. O primeiro fala por si: Hanns Sachs leu Steifleinenheit [pedantismo] ao invés de Stilfeinheit [fineza de estilo], quando 
lia observações que haviam sido escritas por um autor que ele admirava muito, observações essas que enalteciam efusivamente um historiador que, ao contrário, não lhe era nada simpático (Ibid., p. 119). O segundo exemplo, de interpretação bem mais complexa, consiste na substituição da forma correta ich [eu] por nicht [não], feita por um tenente hospitalizado que sofria de uma neurose traumática de guerra, ao ler em voz alta, para um colega, um poema cujo autor havia sido prematuramente morto em combate:
Wo aber steht's geschrieben, frag' ich, dass von allen
Ich übrig bleiben soll, ein anderer für mich fallen?
Wer immer von euch fällt, der stirbt gewiss für mich;
Und ich soll übrig bleiben? Warum denn nicht?
Mas onde está escrito, pergunto, que de todos
Devo eu sobreviver, que outro há de cair por mim?
O que tomba dentre vós, decerto é por mim que morre;
E devo eu permanecer? Por que nãoleu?

Freud conclui sua interpretação desse lapso atribuindo ao tenente o seguinte pensamento temeroso, inconscientemente recalcado: "curado... voltar à ativa... por que eu?" (Ibid, pp. 122-123).

Os tradutores frequentemente cometem esses lapsos (facilmente comprováveis, diga-se de passagem), lendo no texto fonte uma palavra materialmente semelhante àquela que de fato está escrita, ou mesmo uma palavra que não está lá. Creio ser de interesse trazer o que Freud diz sobre esses lapsos de leitura, quando distingue duas situações: em uma delas, é o leitor que tem uma participação mais forte na constituição do lapso, e na outra, ao contrário, é principalmente o texto que contribui para a sua formação. Leiamos:

num imenso número de casos é a predisposição do leitor que altera a leitura e introduz no texto algo que corresponde a suas expectativas ou que o está ocupando. A única contribuição que o próprio texto precisa fazer ao lapso de leitura é fornecer alguma semelhança na imagem da palavra, que o leitor possa modificar no sentido que quiser. (Ibid., p. 121)

Num segundo grupo de casos, é muito maior a participação do texto no lapso de leitura:

Ele contém algo que mexe com as defesas do leitor - alguma comunicação ou exigência que lhe é penosa - e que, por isso mesmo, é corrigido pelo lapso de leitura, no sentido de um repúdio ou uma realização de desejo. Nesses casos, evidentemente, somos forçados a presumir que, de início, o texto foi corretamente entendido e julgado

Revista Escrita 
pelo leitor, antes de passar pela retificação, embora sua consciência nada tenha sabido dessa primeira leitura. (Ibid., p. 122)

Quando traduzimos, cometemos alguns lapsos que não conseguimos identificar se ocorreram ao lermos o texto original ou ao escrevermos o texto traduzido. Freud relata um desses casos, o qual envolve a omissão de uma palavra crucial - effektiv ("efetivo") - em uma tradução húngara de uma das seções da lei estabelecida entre a Áustria e a Hungria, em 1867, relativa às obrigações financeiras dos dois países. De acordo com Freud, esse lapso histórico teria contribuído para prejudicar financeiramente a Áustria, satisfazendo ao menos em parte a "provável tendência inconsciente" dos redatores do legislativo húngaro a concederem o mínimo possível de vantagens àquele país (Ibid., p. 135).

Acerca dessa mesma espécie de lapso, cabe uma referência ao famoso conto $O$ tradutor cleptomaníaco - escrito pelo húngaro Dezsö Kosztolányi, no início do século - que, como o próprio título sugere, constitui uma expressiva parábola não só do preconceito segundo o qual toda tradução pressupõe uma perda relativamente ao original, como também das reais omissões e distorções que muitas vezes os tradutores inconscientemente cometem. Vejamos mais abaixo o que diz o narrador do conto, também personagem e amigo pessoal do tradutor-personagem, ao constatar a imensa fortuna em móveis e imóveis que este havia "surrupiado" e por isso concluir que o tradutor era mesmo "escravo" de um vício (uma psicopatologia) que, apesar de sua determinação consciente, não conseguia vencer. Note-se que, assim como no exemplo da tradução húngara que Freud apresenta, foi só a partir do cotejo com o original que o "crime" pôde ser constatado:

fiquei extremamente surpreso quando, passados alguns dias, o editor me comunicou que a tradução do meu protegido era totalmente inutilizável [...] O editor, sem nada dizer, entregou-me o manuscrito. Comecei a ler o texto. Soltei um grito de admiração. Frases claras, mudanças engenhosas, montagens linguísticas espirituosas se sucediam, muito mais dignas que o original [uma novela inglesa, sabidamente um "lixo"]. Espantado, perguntei ao editor que defeito tinha encontrado. Ele me entregou o original inglês [...]. Por meia hora, mergulhei alternadamente no original e no manuscrito. Ao final, levantei-me consternado. Declarei que ele estava com toda a razão. (Kosztolányi, 1996, pp. 8-9)

O narrador faz como que um levantamento dos "furtos": as "trinta e seis janelas do velho castelo", no original, são reduzidas a "dezessete janelas do velho castelo", na tradução; os "quatro lustres de cristal" passam a ser apenas "dois"; e as "mil e quinhentas libras" tiradas da carteira por um conde, "cento e cinquenta". Se houve aí furto de riquezas, mas não de palavras, já no trecho a seguir houve a ocorrência de 
ambos, conforme, mais uma vez, atesta o narrador com base em seu confronto da tradução com o original:

"A condessa Eleonora estava sentada num dos cantos do salão de baile, vestida para a noite, usando as velhas joias da família: tiara de diamantes, [...] pérolas verdadeiras de brilho opaco; seus dedos quase se enrijeciam com os anéis de..." $\mathrm{O}$ manuscrito húngaro, para minha grande surpresa, assim trazia: "A condessa Eleonora estava sentada num dos cantos do salão de baile, vestida para a noite." Sem mais. A tiara de diamantes, o colar de pérolas, os anéis de brilhante, safira, esmeralda haviam desaparecido. (Ibid., p. 9)

Curioso observar que os lapsos cometidos pelo tradutor, em geral tratados simplesmente como erros por desatenção, costumam ser classificados como sendo de três espécies: omissões, como os casos vistos logo acima; alterações ou distorções, como ocorrido no lapso em que Freud escreveu Asdrúbal em vez de Amílcar ou nos lapsos de leitura cometidos por Hanns Sachs e pelo tenente nada desejoso de voltar à guerra; e acréscimos. Exemplos deste último tipo ainda não apareceram no presente trabalho, mas não estão ausentes do livro de Freud que nos inspira tanto: casos de evidente excesso de um texto em relação a seu respectivo original ocorriam, segundo Freud, em trechos particularmente importantes de extensos pareceres médico-legais. Tal espécie de lapso consistia em repetições muito frequentes de uma mesma palavra, o que lhe sugeria a interpretação de que o autor do lapso, um copista, porque "entediado com seu papel impessoal, introduzisse seu próprio comentário: 'É exatamente o meu caso', ou 'o mesmo acontece conosco'." Vale aqui lembrar a analogia muitas vezes feita entre tradução e cópia, dada a natureza de impessoalidade ou neutralidade normalmente exigida em ambos os ofícios. As repetições de palavras constituem um tipo de lapso de escrita plenamente visível e muito frequente, em geral considerado um erro de digitação e, secundariamente, de revisão. Para o presente trabalho, esse lapso importa na medida em que ocorre na escrita de um sujeito que, como parece claro na interpretação de Freud, deseja a "exteriorização de um 'eu também,", assim contrariando o recalcamento operado pela "impessoalidade" exigida (1996, v. VI, pp. 135-136).

As pessoas costumam ignorar ou minimizar a ação do inconsciente nesses lapsos, e, como rapidamente indicado mais acima, acreditam que eles resultam simplesmente de uma diminuição quantitativa de atenção. Freud defende o contrário, dizendo que na maioria das vezes o desvio de atenção não é a causa do erro, mas que esse desvio é, ele próprio, efeito de um pensamento alheio que se impôs.

Creio que para o leitor que desconhece a obra freudiana pode ser interessante ter um primeiro contato, ainda que breve, com o lapso que talvez seja o mais discutido entre os psicanalistas, um lapso de fala cometido por Freud em razão de seu "esquecimento" do nome do pintor Signorelli. Não devo aqui apresentá-lo em detalhe, 
devido à extensão e riqueza de todos os elementos que nele estão imbricados, ou seja, que o sobredeterminaram. Mas, para um melhor entendimento do fenômeno psíquico de que tratamos, do entrelaçamento do desejo do inconsciente com a língua, me parece bastante revelador mostrar, a partir do quadro feito pelo próprio Freud, os principais significantes da cadeia envolvida em seu esquecimento e posteriores lapsos:

Signorelli
Herzegovina
$\begin{gathered}\text { Herr, o que hei de dizer? (frase-chave da anedota) } \\ \text { temas da morte e sexualidade }\end{gathered}$ Trafoi
(esses últimos representam pensamentos recalcados)

Vejamos brevemente como se situa, no discurso, cada um desses significantes: Signorelli, o nome esquecido por Freud em conversa com outro passageiro, desconhecido, durante uma viagem de trem; Botticelli e Boltraffio, os nomes de dois outros pintores, erroneamente lembrados; Herzegovina (destino final de sua viagem) e Bósnia, nomes que haviam feito parte de uma conversa (com o mesmo companheiro de viagem) imediatamente anterior àquela em que se deu o esquecimento seguido de lapso; Herr, o vocativo da frase-chave de uma anedota sobre uma peculiaridade sexual dos turcos da Bósnia, a qual Freud havia pensado contar, mas que foi recalcada, por ele considerar delicado tocar "naquele tema" com um estranho; e, por último, Trafoi, nome de um lugarejo ao qual estava associado um outro pensamento que, doloroso, precisava ser evitado e cujo núcleo constituía-se naquele tema da sexualidade, ao lado do tema da morte - centrais na psicanálise (Ibid., pp. 20-24).

Sendo todo lapso de língua inegavelmente um erro (isto é, uma ruptura radical com o que é estabelecido, previsível) e sendo de fato uma formação do inconsciente (ou, em outras palavras, uma daquelas situações em que o pensamento ou o desejo inconscientes saíram vitoriosos da luta contra uma intenção considerada consciente), podemos ser levados a deduzir que as propostas de Freud basearam-se exclusivamente na dicotomia incorreto/correto, o que, por sua vez, implicaria em uma oposição binária entre, de um lado, formações do inconsciente e, de outro lado, formas resultantes de uma intenção consciente inabalável, de uma revisão ou elaboração estritamente secundária. Mas Freud foi muito enfático quando afirmou, em trabalhos posteriores, que parte do Ich (ego, eu) também é inconsciente. Em Algumas lições elementares de psicanálise, ele diz que "a consciência é apenas uma qualidade inconstante"; que "a consciência só nos pode oferecer uma cadeia incompleta e rompida de fenômenos"; que "o psíquico é em si mesmo inconsciente", ou, que "o inconsciente é o verdadeiro psíquico" (1996, v. XXIII, pp. 305-306). Podemos perceber nessas afirmações uma verdadeira revolução em relação ao sujeito da razão cartesiano: Freud, podemos afirmar 
com Derrida, não só inverte os termos da hierarquia tradicionalmente presentes na dicotomia consciência/inconsciente, colocando o inconsciente na posição superior, como também destrói a própria ideia que sempre se teve de consciência ou razão ao trazer o inconsciente para essa esfera.

Observando-se inúmeras formações linguísticas polêmicas e sabendo-se que a ação do inconsciente é tão poderosa e ampla, parece-me possível pensar que seu efeito na língua não esteja restrito aos lapsos (e aos chistes). Proponho pensarmos em escolhas verbais que, diferentemente dos lapsos, não chegam a perturbar o código de maneira drástica; escolhas que não produziriam absurdos completos, que não resultariam em uma escrita explícita do sujeito do inconsciente. Seriam formações linguísticas que, numa série gradativa de (in)aceitabilidade, escapariam aos extremos, sendo a um só tempo corretas $e$ incorretas. Essas formas - que chamo de singularidades - de fato consistiriam em formações do inconsciente, efeitos de uma elaboração secundária, intelectual, invadida pelo desejo, mas menos explícitas, mais sutis, talvez devido ao fato de o inconsciente sair apenas parcialmente bem sucedido de sua luta contra as forças recalcadoras. A noção de singularidade, assim concebida, talvez pudesse ser proveitosamente estendida ao campo dos estudos de tradução, contribuindo para esclarecer o tema deste artigo: o sujeito que traduz.

Para concluir, proponho que consideremos o seguinte exemplo de singularidade no processo tradutório: certa vez, uma de nossas alunas da graduação reagiu com desagrado à correção de certa palavra que ela havia usado em sua tradução de um poema de Sylvia Plath. Tratava-se da tradução de picking up por "colando", à qual fora contraposta a forma "catando". Surpresa diante de sua reação, pedi que ela justificasse a escolha que havia feito. Após algum tempo em silêncio - quando, ao que parecia, ela estava construindo pela primeira vez a história de sua escolha, daquele momento singular em que o sujeito e o texto se constituíram mutuamente - ela disse:

quando eu era criança, minha mãe, ao confeitar bolos [para vender], várias vezes me dizia que a cola do bolo era o glacê e, de fato, ela tinha razão. Havia ocasiões em que via aqueles bolos completamente espedaçados devido à fofura da massa. Mas, com um pouco de paciência e com a ajuda do glacê, a restauração do bolo era possível. O glacê, além de ser cola, era também o único remédio. (grifos meus) ${ }^{7}$

Abaixo, mostrarei duas estrofes do poema original e da tradução da aluna, e destacarei os significantes que formaram um tipo de rede em que a tradutora foi pega sem perceber, durante todo o processo de tradução pelo qual passou. Nessa rede surgiu a palavra "colando" para picking up em vez de outras formas mais previsíveis como "catando" ou "pegando": 


\section{(...)}

What is so real as the cry of a child?

A rabbit's cry may be wilder

But it has no soul.

Sugar can cure everything, so Kindness says.

Sugar is a necessary fluid,

Its crystals a little poultice.

$\mathrm{O}$ kindness, kindness

Sweetly picking up pieces!

My Japanese silks, desperate butterflies,

May be pinned any minute, anaesthetized.
(...)

O que é mais puro que o choro de um filho?

$\mathrm{O}$ choro de um coelho pode ter mais ardor

Mas ele não tem alma.

O açúcar cura tudo, diz a Bondade.

Açúcar, um fluido necessário,

Seus cristais, um pequeno cataplasma.

Ó bondade, bondade

Colando os cacos com doçura!

Minhas sedas japonesas, desesperadas borboletas,

Alfinetadas a qualquer minuto, anestesiadas.

\section{(...)}

child - filho - a tradutora quando criança

sugar-crystals-pieces - açúcar-cristais-cacos - os bolos de sua mãe, seus bolos cure-poultice - cura-cataplasma - a restauração do bolo, o remédio, o glacê: necessary fluid-fluido necessário que restaura, cura, cola! (Frota, 2007, p. 10)

O encadeamento desses significantes que levaram a tradutora até "colando" parece ter-se construído mais em função dos sentidos que provocaram em sua interpretação do poema do que em função de seu aspecto propriamente material. Quando os significantes se enlaçam movidos por essa força, digamos, interpretativa, pelos efeitos de sentido mobilizados, dá-se o que Freud denomina "pontes associativas". Estas podem coexistir ou não com as pontes verbais, noção que ficou bastante explícita tanto no lapso de escrita que envolveu os nomes Aníbal-Amílcar-Asdrúbal, quanto no lapso de leitura que substituiu a forma correta nicht por Ich, bem como, creio, na tradução de rocking chair por "cadeira de rodas" já que podemos enxergar, graças ao 
relato da tradutora, não só a ponte associativa entre avô-família-excesso de trabalho etc. etc., como também a ponte verbal constituída por "ro-", primeira sílaba da expressão inglesa e da palavra "substitut[a] de uma ocultação ou recalcamento intencionais" (Freud, 1996, v. VI, p. 220).

Espero que esta reflexão e sobretudo as experiências de escrita do desejo inconsciente que foram apresentadas tenham podido contribuir para o entendimento de que a tradução, como qualquer forma de re-escrita, não surge de mão mecânica, neutra e obediente a um significado já fixado em uma gramática, em um dicionário, em uma língua tomada como Uma, como idêntica a si própria; nem se origina em uma cabeça que se suponha livre e imaginativa, capaz de racional, consciente e autonomamente reinventar ou quebrar o tecido uniforme da língua. Para fechar com um dizer positivo, recorro novamente a Freud, que afirmou em Moisés e o monoteísmo: "o poder criativo de um autor nem sempre obedece à sua vontade: o trabalho avança como pode e com frequência se apresenta a ele como algo independente e até mesmo estranho." (Freud, 1996, v. XXIII, p. 118)

\footnotetext{
${ }^{1}$ Este artigo é uma versão adaptada e ampliada do trabalho publicado em Doletiana - Revista de Traducció Literatura i Arts, 2007. (Agradeço à aluna Carolina Pinho da Silva por sua participação na tradução daquele trabalho).

${ }^{2}$ A ideia central do presente artigo bem como vários dos casos apresentados resultam de minha pesquisa de doutorado (v. Frota, 2000).

${ }^{3}$ Como diz a famosa frase de Jonathan Culler, meaning is context-bound.

${ }^{4}$ No volume da revista Meta publicado em 1982 e dedicado à articulação dos campos da tradução e da psicanálise, encontramos apenas três autores especializados em tradução - dentre eles Derrida - e dezessete psicanalistas. No volume da TTR publicado em 1998, também dedicado à confluência dos dois campos, os dados biográficos dos onze autores mostram que apenas dois têm uma relação profissional com a tradução.

${ }^{5}$ Não podemos esquecer alguns trabalhos de Freud como Totem e tabu e A civilização e os seus descontentamentos.

${ }^{6}$ Se considerarmos o campo da tradução em sua complexa diversidade atual, sem dúvida ganham relevância não só os lapsos de fala e de escuta, como também a categoria mais ampla dos atos falhos, isto é, "lapsos não-verbais" - pensemos, por exemplo, na fase do trabalho do audiodescritor que consiste fundamentalmente em sua percepção das imagens.

${ }^{7}$ Essa declaração foi transcrita posteriormente pela aluna (v. Prado, 1994).
}

\section{Referências bibliográficas}

CULLER, Jonathan. On deconstruction: theory and criticism after structuralism. London: Routledge \& Kegan Paul, 1987.

DERRIDA, Jacques. Posições. Tradução Tomaz Tadeu da Silva. Belo Horizonte: Autêntica, 2001. 
FREUD, Sigmund. “A psicopatologia da vida cotidiana”. In: SALOMÃO, Jayme (org.) Obras psicológicas completas de Sigmund Freud: edição standard brasileira, v. VI. Tradução Vera Ribeiro. Rio de Janeiro: Imago, 1996.

. "O ego e o id". In: SALOMÃO, Jayme (org.) Obras psicológicas completas de Sigmund Freud: edição standard brasileira, v. XIX. Tradução José Octavio de Aguiar Abreu. Rio de Janeiro: Imago, 1996.

. "Algumas lições elementares de psicanálise" e "Moisés e o monoteísmo". In:

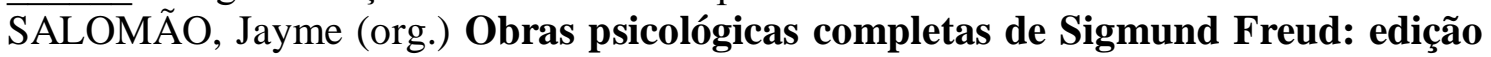
standard brasileira, v. XXIII. Tradução José Octávio de Aguiar Abreu. Rio de Janeiro: Imago, 1996.

FROTA, Maria Paula. A singularidade na escrita tradutora: linguagem e subjetividade nos estudos da tradução, na linguística e na psicanálise. Campinas \& São Paulo: Pontes \& FAPESP, 2000.

. "Erros e lapsos de tradução". In: Cadernos de Tradução, n. XVII, 2006/1, PGET, UFSC, pp. 141-156.

"The unconscious inscribed in the translated text". Doletiana : revista de traducció, literatura i arts 1, Universitat Autònoma de Barcelona, 2007. http://webs2002.uab.es/doletiana/English/Doletiana1-e/Doletiana1e.html

GENTZLER, Edwin (org.). Contemporary translation theories. London \& New York: Routledge, 1993.

HERMANS, Theo. "Introduction: Translation Studies and a new paradigm". In:

(org.) The manipulation of literature - studies in literary translation. London \& Sydney: Croom Helm, 1985.

KOSZTOLÁNYI, Dezsö. "O tradutor cleptomaníaco". In: ___ O tradutor cleptomaníaco. Tradução Ladislao Szabo. Rio de Janeiro: Editora 34, 1996.

LACAN, J. "A instância da letra no inconsciente ou a razão desde Freud". In: Escritos. Tradução Inês Oseki-Depré. São Paulo: Perspectiva, 1978.

LEFEVERE, André \& BASSNETT, Susan. "General editors' preface". In: GENTZLER, Edwin. (org.) Contemporary translation theories. London \& New York: Routledge, 1993.

PRADO, Marilucy. "Kindness/Bondade \& Comentários". In: FERREIRA, A. B. F. e outros (orgs.) Letras em tradução: antologia de poemas traduzidos. Departamento de Letras, PUC-Rio, 1994.

VENUTI, Lawrence. "O escândalo da tradução". Tradução Stela E. O. Tagnin. Tradterm - Revista do Centro Interdepartamental de Tradução e Terminologia, n.3. São Paulo: FFLCH-USP, 1996, pp. 111-122. 